\title{
OBSTRUCTIVE SLEEP APNOEA- PREVALENCE, DIAGNOSIS AND ITS RELATIONSHIP WITH STRESS- A REVIEW OF LITERATURE
}

\author{
Manisha Mangesh Kulkarni1 ${ }^{1}$ Sabita M. Ram²
}

1PhD Scholar, Saveetha Institute of Medical and Technical Sciences, Associate Professor, Department of Prosthodontics, YCMM RDF

Dental College, Ahmednagar, Maharashtra, India.

2Dean/Professor, Department of Prosthodontics, YCMM RDF Dental College, Ahmednagar, Maharashtra, India.

\section{ABSTRACT}

\section{BACKGROUND}

Obstructive sleep apnoea and hypopnoea syndrome is mainly due to repeated airway collapse during sleep. There are many aetiological factors associated with this disease. The main causative factor being reduced expansion of the pharyngeal muscles, anatomical structures associated and altered respiratory function, which has direct impact on air required for breathing, thereby leading to sleep disturbances. Other causes being macroglossia, tonsillar hypertrophy and structural skeletal disfigurement such as micrognathia and retrognathia. Obesity is one of the risk factors as the neck circumference narrows the airway space, thereby increasing difficulty in breathing, and snoring. This article reviews the diagnosis, treatment and epidemiology of obstructive sleep apnoea.

\section{KEY WORDS}

Sleep Apnoea, Apnoea, Stress, Sleep Disorder, Obstructive Sleep Apnoea Syndrome.

HOW TO CITE THIS ARTICLE: Kulkarni MM, Ram SM. Obstructive sleep apnoea- prevalence, diagnosis and its relationship with stress- a review of literature. J. Evolution Med. Dent. Sci. 2018;7(31):3549-3551, DOI: 10.14260/jemds/2018/797

\section{BACKGROUND}

The fact that some people stop breathing during sleep has been known since ages. Several medical reports, in particular describe OSA symptoms and severely affected patients. In a few decades, OSA has been considered as one of the most commonly and fast affecting diseases in the world with major complications. The first sleep registration has been made by a German, Hans Berger in 1929. Gasault et al gave an association between breathing and daytime sleepiness thus leading to OSA.(1) Overall health of stomatognathic system is based on proper health of oral hard and soft tissue. The subject of sleep medicine offers a great challenge to the dental profession in general and prosthodontists in particular in terms of diagnosis, treatment planning and treatment based on qualitative evidence. OSA is categorised under Sleep-related Breathing Disorder (SBD) by International classification of sleep disorder. It has been strongly believed that sleep disordered breathing affects the sleep cycle.(2)

Obstructive Sleep Apnoea (OSA) is a very common disorder affecting people of all ages, but the prevalence is more in the middle-aged and elderly. People who are affected by sleep apnoea experience obstruction and repeated collapse of the upper airway during sleep, resulting in reduced airflow (Hypopnoea) or complete cessation of airway (Apnoea), arousals from sleep and oxygen desaturation. Cardiovascular disease, hypertension, noninsulin-dependent diabetes and increased likelihood of motor vehicle and other accidents due to daytime sleepiness all these are some of the adverse effects of obstructive sleep apnoea.

'Financial or Other Competing Interest': None.

Submission 02-07-2018, Peer Review 20-07-2018,

Acceptance 23-07-2018, Published 30-07-2018.

Corresponding Author:

Dr. Manisha Mangesh Kulkarni,

Balaji Paediatric and Dental Hospital,

Opposite Bedekar Classes, Ghumare Lane,

Near Asha Square, Ahmednagar-414001,

Maharashtra, India.

E-mail: drmanishak05@gmail.com

DOI: $10.14260 /$ jemds $/ 2018 / 797$

\section{(c) $($ ) $\$$}

Decreased sleep and daytime sleepiness has great influence on stress related problems. Hence, stress is associated with obstructive sleep apnoea.

In the middle-aged group OSA has negative impact on behaviour and normal health of the individual, especially in the age group of 20 - 50 years. Obstructive sleep apnoea being an independent risk factor to diseases like hypertension, heart attack, cardiovascular events and arrhythmias. Unfortunately, it is a common chronic disease that greatly conditions the life of the patient.(1) Stress being one of the important factors, which can be linked with sleep apnoea. Many medical conditions are linked to sleep apnoea and stress indirectly and it varies from patient to patient.(2)

\section{Sleep Apnoea}

There are four main types of Sleep Apnoeas-

1. Obstructive Sleep Apnoea (OSA): When the upper airway collapses; there is complete cessation of airflow leading to difficulty in breathing. OSA is the most common form of apnoea.

2. Complete Sleep Apnoea: It is a combination of obstructive sleep apnoea and central apnoea. Episode usually begins with no breathing effort (central sleep apnoea), hence breathing efforts start but airway is blocked (OSA).

3. Central Sleep Apnoea: Here the brain fails to signal the muscles needed to breathe. This type is not as common as obstructive sleep apnoea.

4. Sleep Hypoventilation: It is associated with obesity, carbon dioxide level and low oxygen level during sleep and during the day.

Obstructive Sleep Apnoea are basically Divided as-

a. Mild, 5-15 events per hour.

b. Moderate, 15-30 events per hour.

c. Severe, more than 30 events per hour.

Symptoms and Signs of Sleep Apnoea

Particular Signs and Symptoms of Obstructive Sleep Apnoea- 
- Depression.

- Family history of obstructive sleep apnoea.

- Fatigue.

- Gasping or choking during sleep.

- High blood pressure.

- Impotence.

- Irritability.

- Lack of concentration.

- Large thick neck.

- Males (40 years).

- Memory loss.

- Morning headaches.

- Obesity.

- $\quad$ Recessed chin or large tonsils.

- $\quad$ Snoring with pauses in breathing.

- Unexplained excessive daytime sleepiness.

\section{Prevalence}

OSA is a very common disease which has been neglected and now it is becoming more widely recognised by the population. The extent of undiagnosed OSA is about $5 \%$ of adults and $75 \%$ of obstructive sleep apnoea is left undiagnosed.(3) Wisconsin sleep cohort study, Young et al evaluated that obstructive sleep apnoea is a common disease in middle-aged individuals who were diagnosed by polysomnography. The prevalence of OSA varies significantly based on the population being studied and how OSA is defined. The prevalence of OSA is reported to be around $2 \%$ for women and $4 \%$ for men,(3) whilst habitual snoring affects about $3 \%$ to $12 \%$ of the total world population. $(4,5)$ The majority of patients who suffer from sleep apnoea are middle-aged men, though women and an increasing number of children are also affected by the disease.(6) Currently, the prevalence of snoring in children is estimated to be about $0.8 \%$ to $24 \%$ with around $1 \%$ to $5 \%$ suffering from OSA.(7) Obstructive sleep apnoea is considered to be the second largest disorders amongst all respiratory and sleep disorders. OSA is considered most commonly in adult population, mainly seen in more than 30 years of age group. One amongst 5 adults suffer from OSA syndrome (moderate) and one among every 15 presents moderate-to-severe OSA.(8) This syndrome mainly involves pressurised breathing, arousals, lack of oxygen in the blood stream, thereby leading to the disturbed sleep.(1) OSA percentage is mainly seen more in males than in females; $70 \%$ to $80 \%$ of the population suffering from this syndrome remain undiagnosed.(9) The consequences of untreated OSA are wide ranging and postulated to result from the fragmented sleep; intrathoracic pressure swings and disturbances in breathing during sleep. The current scenario states that moderate-to-severe OSA are now $10 \%$ among 30 - 49 years old men; $17 \%$ among $50-70$ year old men. This shows that there is marked increase in the obstructive sleep apnoea in the past two decades. Obesity being one of the major risk factors leading to high prevalence of OSA.

\section{Diagnosis}

Easier and less time-consuming method of diagnosing sleep apnoea is by lateral cephalometric analysis. Many other tests are available for diagnosing obstructive sleep apnoea like polysomnography which monitors the respiration, sleep state, snoring and pulse oximetry records. It also records number of apnoea-hypopnoea index, which helps in diagnosing obstructive sleep apnoea syndrome. When AHI $>30$ it indicates severe apnoea, while AHI 15 - 30 denotes moderate apnoea and an AHI score of $<15$ shows mild apnoea.

Basically, diagnosis of obstructive sleep apnoea is done under two broad categories- Subjective and Objective tools. Subjective assessment includes sleep questionnaires like Stop-Bang, Epworth's sleepiness scale and Stanford sleepiness scale. Loss of sleep in any case leads to increase in the values of these scales. All these questionnaires have sensitivity up to $74 \%$ to $84 \%$.(10) $^{(10}$

Objective assessment includes multiple sleep latency tests, in which patients are allowed four or five 20 minutes opportunities to sleep at regular intervals of time during daytime. In a comfortable setting, patient's sleep tendency is noted. This method is reliable, but cannot be co-related much with obstructive sleep apnoea. So this test is not frequently used. Maintenance of Wale's test is similar to MSLT with the difference that sleep is assessed by exposure to various external stimuli. Polysomnography is considered to be the most accurate method for the diagnosis of obstructive sleep apnoea. It consists of Electroencephalogram (EEG) to monitor brain activity, Electromyogram (EMG) to monitor limb activity, oral and nasal thermistors, pulse oximetry and many more complex systems to record the AHI index and sleep cycle and respiratory functions during sleep.(11) PSG is one of the important diagnostic tools for many sleep related breathing disorders. In patients who are on CPAP in cases of severe obstructive sleep apnoea, repeated polysomnographic recordings help in assessing the prognosis. Cephalograms are the gold standard method for evaluation of obstructive sleep apnoea. They help in analysing soft tissue and hard tissue parameters. Oropharyngeal region can be studied in detail for any abnormalities. Other diagnostic methods are portable sleep monitoring device for use at home, automatic pressure titrating CPAP, anthropometric measurements like neck circumference, BMI, laryngeal and nasopharyngeal morphology, MRI, CT scan and acoustic reflections.(8,11)

Obstructive sleep apnoea can lead to the sympathetic activation, oxidative stress, congestive cardiac failure, metabolic dysregulation, sleep fragmentation and neurohumoral changes, hence leading to other deadly diseases like diabetes, cerebrovascular disease and hypertension.(11)

\section{Obstructive Sleep Apnoea and Stress}

The Hypothalamic Pituitary Adrenal (HPA) axis mediates the reaction to acute physical and psychological stress. HPA and sleep interact in multiple ways. Sleep, in particular deep sleep has an inhibitory influence on the HPA axis,(12) whereas activation of the HPA axis or administration of glucocorticoids can lead to arousal and sleepiness. Obstructive sleep apnoea syndrome and stress are indirectly related to each other. Repeated arousal from sleep and mental fatigue may lead to mental as well as physical stress. Stress is a general wear and tear of the body causing psychophysiological changes that occur when the individuals are exposed to the situation.(13) Stress from day-to-day life and occupational burden gradually affects the sleep, which in turn may lead to many sleep disorders, one amongst them being obstructive sleep apnoea. Sleep disturbances can lead to impairment of work efficiency, muscle tension, tachycardia 
and soreness of mouth which can create emotional disturbances leading to stress and emotional fatigue.(14)

\section{CONCLUSION}

Stress is an individual's response to change in circumstances, or to a threatening situation. It can be viewed as personal reaction to an external event/ demand like writing an exam or to an internal state of mind like worrying about an exam. Obstructive sleep apnoea syndrome is a common sleep disorder that occurs due to repetitive partial or complete obstruction of upper airway and is mainly characterised by frequent episodes of cessation of breathing during sleep, which will be lasting for more than 10 seconds. Many a times, undiagnosed OSA and mild-to-moderate OSA can also lead to morbidity and mortality.(15,16) The damage caused by sleep fragmentation in people affected by OSA can affect their life emotionally, leading to not only physical symptoms but also tiredness, drowsiness and stress.

\section{REFERENCES}

[1] Rosen CL. Obstructive sleep apnea syndrome (OSAS) in children: diagnostic challenges. Sleep 1996;19(10 Suppl):S274-7.

[2] Trakada G, Chrousos G, Pejovic S, et al. Sleep apnea and its association with stress system, inflammation, insulin resistance and visceral obesity. Sleep Med Clin 2007;2(2):251-61.

[3] Bhamrah G, Dhir A, Cash A, et al. Patient's experience of treatment for sleep apnoea with a mandibular advancement splint. Surgeon 2015;13(5):256-62.

[4] Cossellu G, Biagi R, Sarcina M, et al. Three-dimensional evaluation of upper airway in patients with obstructive sleep apnea syndrome during oral appliance therapy. J Craniofac Surg 2015;26(3):745-8.

[5] Marcus CL, Brooks LJ, Draper KA, et al. Diagnosis and management of childhood obstructive sleep apnea syndrome. Pediatrics 2012;130(3):576-84.
[6] Conley RS. Management of sleep apnea: a critical look at intra-oral appliances. Orthod Craniofacial Res 2015;18 Suppl 1:83-90.

[7] Carvalho FR, Lentini-Oliveira DA, Carvalho GM, et al. Sleep-disordered breathing and orthodontic variables in children-Pilot study. Int J Pediatr Otorhinolaryngol 2014;78(11):1965-9.

[8] Young T, Peppard P, Palta M, et al. Population-based study of sleep-disordered breathing as a risk factor for hypertension. Arch Intern Med 1997;157(15):174652.

[9] Punjabi NM. The epidemiology of adult obstructive sleep apnea. Proc Am Thorac Soc 2008;5(2):136-43.

[10] Ancoli-Israel S, Kripke DF, Klauber MR, et al. Sleep disordered breathing in community-dwelling elderly. Sleep 1991;14(6):486-95.

[11] Sharma H, Sharma HK. Overview and implications of obstructive sleep apnoea. The Indian Journal of Chest Diseases and Allied Sciences 2008;50:137-50.

[12] Weitzman ED, Zimmerman JC, Czeisler CA. Cortisol secretion is inhibited during sleep in normal man.J Clin Endocrinol Metab 1983;56(2):352-38.

[13] LippMEN. O Stress: Conhecer e Enfrentar. $5^{\text {th }}$ edn. São Paulo, Brazil: Ed. Contexto 2003.

[14] Bahammam A, Delaive K, Ronald J, et al. Health care utilization in males with obstructive sleep apnea syndrome two years after diagnosis and treatment. Sleep 1999;22(6):740-7.

[15] He J, Kryger MH, Zorick FJ, et al. Mortality and apnea index in obstructive sleep apnea. Experience in 385 male patients. Chest 1988;94(1):9-14.

[16] Glebocka A, Kossowska A, Bednarek M. Obstructive sleep apnea and the quality of life. J Physiol pharmacol 2006;57(Suppl 4):111-7. 